\title{
Characteristics and survival of patients prescribed long-term oxygen therapy outside prescription guidelines
}

\author{
D. Veale, E. Chailleux, A. Taytard, J.P. Cardinaud
}

Characteristics and survival of patients prescribed long-term oxygen therapy outside prescription guidelines. D. Veale, E. Chailleux, A. Taytard, J.P. Cardinaud. OERS Journals Ltd 1998.

ABSTRACT: Criteria for the prescription of long-term oxygen therapy (LTOT) have been published by academic societies and regulatory bodies, but many prescriptions for LTOT do not fulfil these criteria.

Demographic, functional data and survival were compared in chronic obstructive pulmonary disease (COPD) patients with different levels of oxygenation, i.e. arterial oxygen tension $\left(\mathrm{Pa}, \mathrm{O}_{2}\right)<8 \mathrm{kPa}$ or $\mathrm{S} 8 \mathrm{kPa}(60 \mathrm{mmHg})$, at the time of initial registration in the ANTADIR Observatory. Data were collected between 1984-1995. Selection criteria were a diagnosis of COPD or emphysema with forced expiratory volume in one second (FEV1) $<80 \%$ pred, FEV1/vital capacity (VC) $<70 \%$ and age between 18-75 yrs.

Of 7,700 patients prescribed LTOT $18.5 \%$ had stable $P a, O_{2} \breve{S} 8 \mathrm{kPa}$. While the FEV1 was the same they differed from the patients with more severe hypoxaemia in having a higher rate of diagnosis of primary emphysema and a lower arterial carbon dioxide tension $\left(\mathrm{Pa}_{1}, \mathrm{CO}_{2}\right)$. In this group of patients LTOT was more frequently administered as liquid oxygen than in other patients on LTOT. The survival of these patients was reduced compared to the general population of the same age and sex but comparable to that of patients with a $\mathrm{Pa}, \mathrm{O}_{2}$ between $6.7-8 \mathrm{kPa}(50-60 \mathrm{mmHg})$.

Patients prescribed long-term oxygen therapy with an arterial oxygen tension Šs $\mathrm{kPa}(60 \mathrm{mmHg})$ in the ANTADIR network were shown to have severe chronic obstructive pulmonary disease on the basis of spirometry and their survival was similar to that of more hypoxaemic patients. Randomized controlled trials of the effect of

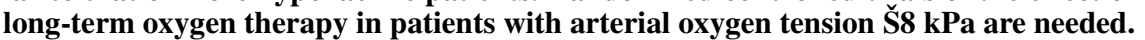
Eur Respir J 1998; 12: 780-784.
Groupe Observatoire ANTADIR, CMTS, Paris, France.

Correspondence: D. Veale

CMTS, ANTADIR

66 Bld St Michel

75006 Paris

France

Fax: 33144414911

Keywords: Guidelines

long-term oxygen therapy

oxygen

prescription

survival

Received: September 21997

Accepted after revision March 11998
Studies have shown that long-term oxygen therapy (LTOT) improves survival in patients with chronic obstructive pulmonary disease (COPD) $[1,2]$. These initial studies were carried out using strictly defined protocols and in narrowly defined groups of patients. Subsequently, patients have been widely prescribed LTOT on the basis of these studies. In 1995 it was reported that close to 800,000 patients $(280 / 100,000)$ in the USA were receiving LTOT at an annual cost of US\$1.8 billion [3]. In France in 1996 17,500 patients were receiving LTOT in the ANTADIR network and an estimated similar number in the private sector $(\sim 70 / 100,000)$.

Criteria for the prescription of LTOT have been published by academic societies and regulatory bodies [4-6]. Surveys have shown that many prescriptions for LTOT do not fulfil published criteria [7-9]. MoRrison et al. [10] showed that only $14 \%$ of patients with COPD and receiving LTOT in Scotland fulfilled all of the relative criteria for the prescription of LTOT.

Association Nationale pour le Traitement à Domicile de l'Insuffisance Respiratoire (ANTADIR) is the co-ordinating headquarters for 33 federated nonprofit associations delivering home treatment to patients with chronic respiratory insufficiency (CRI) in France [11]. The federated

$\overline{\text { For editorial comments see page } 756}$ associations manage the homecare of nearly $70 \%$ of all patients treated at home for CRI. ANTADIR collects data on all patients managed by its regional associations and this forms the basis of a database called the Observatory. An appreciable proportion of patients with COPD in the Observatory do not fulfil the established criteria for starting LTOT [11]. This has led us to analyse the data in this Observatory to describe the situation of patients prescribed LTOT outside guidelines.

Follow-up studies on unselected groups of patients showed a two-year survival of only $46 \%$ in 217 COPD patients on LTOT in the Belgian register [12] and similar results $(54 \%)$ for 393 patients in the Swedish register [13]. Thus, as a secondary aim the survival of patients with arterial oxygen tension $\left(\mathrm{Pa}_{\mathrm{a}} \mathrm{O}_{2}\right) \mathrm{S} 8 \mathrm{kPa}(60 \mathrm{mmHg})$ was examined, to determine whether this cut-off point clearly demarcated a different category of patient.

\section{Patients and methods}

\section{Collection of data}

Since 1984, the characteristics of patients and their outcome have been collected prospectively in 25 associations, 
managing $79 \%$ of the patients of the ANTADIR network. Information concerning the patient's characteristics was taken from the Social Security form filled in by the prescribing physician. At entry, this form contains information about the patient's age, sex, height, weight, the cause of their CRI, the forced expiratory volume in one second (FEV1) and vital capacity (VC) and arterial blood gases (ABG) in room air. The form specifies the equipment being used at home, the daily use of oxygen therapy, the mode of administration and the flow rate prescribed. On follow-up, treatment modifications, treatment withdrawal or death is noted. All of these data are collected, entered into a computerized database in each regional association and centralized at ANTADIR for an annual report and a national database. The anonymous registration of patients was approved by the Commission Nationale de l'Informatique et des Libertés (CNIL), the French equivalent of the Data Protection Council.

\section{Patient selection}

The patients selected were those equipped with LTOT between January 11984 and December 311995 who were registered with the diagnosis of chronic bronchitis and/or emphysema without any other contributing cause of respiratory failure. Patients studied were aged 18-74 yrs inclusive with an $\mathrm{FEV} 1 / \mathrm{VC}<70 \%$ and an $\mathrm{FEV} 1<80 \%$ predicted [14]. Older patients were likely to have multiple pathologies and a very high rate of transfer to long-term care units.

\section{Statistical analysis}

The patients were divided into two classes according to whether their $\mathrm{Pa}_{2} \mathrm{O}_{2}$ in air at the time of installation of LTOT was $<8 \mathrm{kPa}$ or $\breve{S} 8 \mathrm{kPa}(60 \mathrm{mmHg})$. The demographic and functional characteristics of the patients in these two classes were compared by the Chi-squared test and the Student t-test. A graphic analysis of the variations of each of these variables in relation to the $\mathrm{Pa}, \mathrm{O}_{2}$ divided into classes of $1.3 \mathrm{kPa}(10 \mathrm{mmHg})$ was also carried out. Survival was calculated by the actuarial method from the first day of home treatment. Patients lost to follow-up were excluded from the survival analysis on the day of withdrawal from LTOT or transfer to long-term care units. The comparison of survival of patients according to their initial $\mathrm{Pa}, \mathrm{O}_{2}$ was performed using the log-rank test. The survival of the patients was also compared to that of the general population calculated for a population of the same age and sex from the French national statistics (Institut National de la Statistique et des Études Economique) [15].

\section{Results}

A total of 7,700 patients fulfilled the inclusion criteria. These were mostly males $(6,655)$ and the mean age overall was $63.7 \pm 7.6$ yrs $($ mean \pm sD). The principal cause of respiratory failure was chronic bronchitis in 7,086 cases. At the closing date (January 1 1996) 3,940 patients had died, 2,570 were known to be alive and 1,190 patients

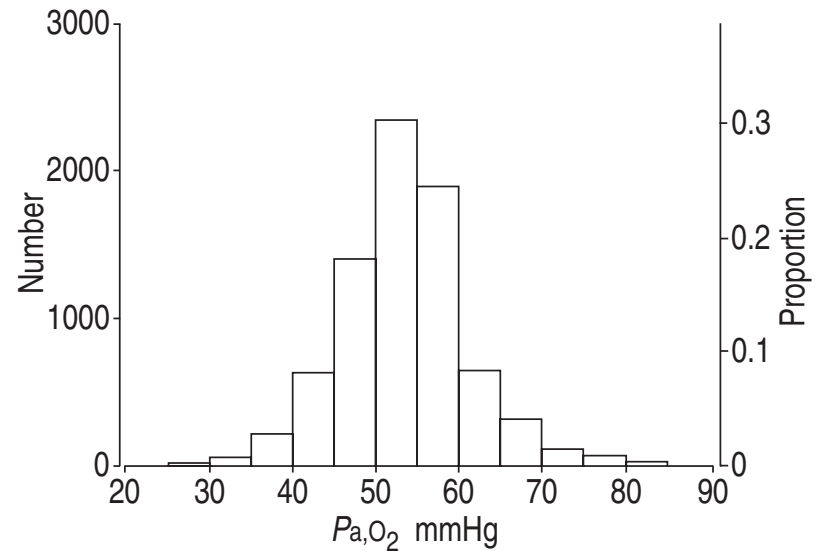

Fig. 1. - Number and proportion of patients at different levels of arterial oxygen tension $\left(\mathrm{Pa}, \mathrm{O}_{2}\right) .(1 \mathrm{mmHg}=0.133 \mathrm{kPa}$. $)$

were lost to follow-up (75\% because of cessation of therapy and $25 \%$ because of transfer to long-term care units).

Figure 1 shows the $\mathrm{Pa}, \mathrm{O}_{2}$ data at the time of prescription of LTOT. Of the patients studied, $18.5 \%(1,425)$ had a $\mathrm{Pa}, \mathrm{O}_{2}>8 \mathrm{kPa}(60 \mathrm{mmHg})$ on initial blood gases. Table 1 compares the functional and demographic characteristics of these patients with those for the group with a $\mathrm{Pa}, \mathrm{O}_{2}<8$ $\mathrm{kPa}(60 \mathrm{mmHg})$ at the time of prescription. There were no age or sex differences between the groups or in body mass index (BMI). The spirometric data were not different and the severity of airflow obstruction was comparable whether or not the patients had a $\mathrm{Pa}, \mathrm{O}_{2}<8 \mathrm{kPa}$. The patients with a higher $\mathrm{Pa}, \mathrm{O}_{2}$ had a significantly lower arterial carbon dioxide tension $\left(\mathrm{Pa}_{\mathrm{a}}, \mathrm{CO}_{2}\right)$. Figure 2 shows $\mathrm{FEV} 1$ as a percentage predicted in relation to the $\mathrm{Pa}, \mathrm{O}_{2}$ and figure 3 shows the relationship between $P \mathrm{a}, \mathrm{O}_{2}$ and the $\mathrm{Pa}, \mathrm{CO}_{2}$.

The daily duration of oxygen therapy prescribed was shorter in the patients with better oxygenation but was near $15 \mathrm{~h}$ per $24 \mathrm{~h}$ (fig. 4) and LTOT was more frequently administered as liquid oxygen to these patients. The proportion of patients labelled as having emphysema was increased in the group with a higher $\mathrm{Pa}_{\mathrm{a}} \mathrm{O}_{2}$ (fig. 5).

Table 1. - Demographic and physiological data according to arterial oxygen tension $\left(\mathrm{Pa}, \mathrm{O}_{2}\right)$

\begin{tabular}{|c|c|c|c|}
\hline & $\begin{array}{c}P \mathrm{a}, \mathrm{O}_{2} \\
<8 \mathrm{kPa} \\
(60 \mathrm{mmHg})\end{array}$ & $\begin{array}{c}{\mathrm{Pa}, \mathrm{O}_{2}} \\
\mathrm{~S} 8 \mathrm{kPa} \\
(60 \mathrm{mmHg})\end{array}$ & $\mathrm{p}$-value \\
\hline Sex M/F & $5417 / 858$ & $1238 / 187$ & 0.591 \\
\hline Age yrs & $63.7 \pm 7.5$ & $63.9 \pm 7.8$ & 0.25 \\
\hline $\mathrm{BMI} \mathrm{kg} \cdot \mathrm{m}^{-2}$ & $24.0 \pm 5.7$ & $24.2 \pm 6.0$ & 0.221 \\
\hline VC \% pred & $61.2 \pm 17.7$ & $61.9 \pm 18.0$ & 0.186 \\
\hline FEV $1 \%$ pred & $32.3 \pm 12.6$ & $32.2 \pm 13.2$ & 0.877 \\
\hline $\mathrm{FEV}_{1} / \mathrm{VC} \%$ & $40.6 \pm 12.0$ & $40.1 \pm 12.8$ & 0.173 \\
\hline TLC $\%$ pred $(n=1747)$ & $90.2 \pm 23.0$ & $93.7 \pm 23.6$ & 0.014 \\
\hline $\mathrm{Pa}_{\mathrm{a}, \mathrm{CO}_{2}} \mathrm{mmHg}$ & $47.7 \pm 8.5$ & $43.6 \pm 7.1$ & $<0.001$ \\
\hline $\begin{array}{l}\text { Daily duration } \mathrm{O}_{2} \\
\text { prescribed }\end{array}$ & $16.2 \pm 2.9$ & $14.9 \pm 3.3$ & $<0.001$ \\
\hline $\begin{array}{l}\mathrm{O}_{2} \text { source: } \\
\text { concentrator/liquid }\end{array}$ & $5951 / 226$ & $1267 / 110$ & $<0.001$ \\
\hline $\begin{array}{l}\text { Diagnosis: chronic } \\
\text { bronchitis/emphysema }\end{array}$ & $5817 / 458$ & $1269 / 156$ & $<0.001$ \\
\hline
\end{tabular}

Data are shown as mean \pm SD. M: male; F: female; BMI: body mass index; VC: vital capacity; $\%$ pred: per cent of predicted value; FEV1: forced expiratory volume in one second; TLC: total lung capacity; $P \mathrm{a}, \mathrm{CO}_{2}$ : arterial carbon dioxide tension. (1 $\mathrm{mmHg}=0.133 \mathrm{kPa}$.) 


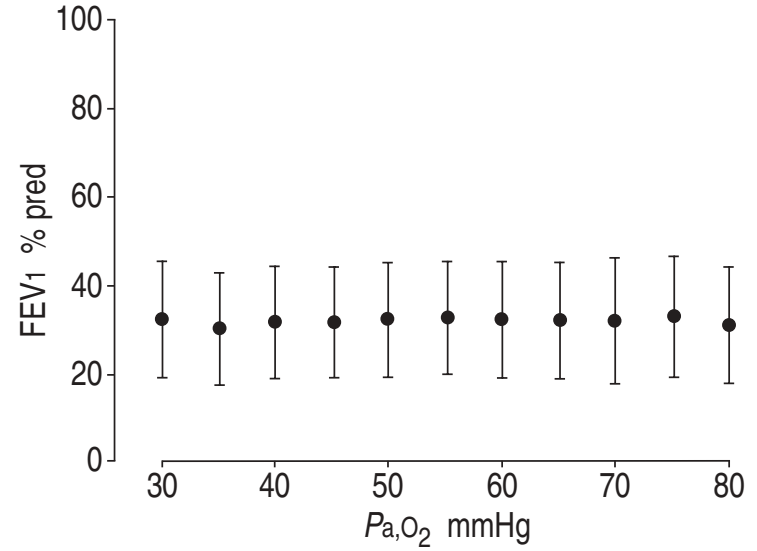

Fig. 2. - Variation in forced expiratory volume in one second (FEV1) in relation to arterial oxygen tension $\left(\mathrm{Pa}, \mathrm{O}_{2}\right)$ (means $\left.\pm \mathrm{SD}\right) .(1 \mathrm{mmHg}=0.133$ $\mathrm{kPa}$.)

Figure 6 shows the survival of the patients in relation to the initial $\mathrm{Pa}, \mathrm{O}_{2}$. The survival of patients with an initial $P \mathrm{a}, \mathrm{O}_{2} \breve{\mathrm{S}} 8 \mathrm{kPa}(60 \mathrm{mmHg})$ was identical to that of patients with a $\mathrm{Pa}, \mathrm{O}_{2}$ between 6.7 and $7.2 \mathrm{kPa}(50$ and $54 \mathrm{mmHg}$ ) and between 7.3 and $7.9 \mathrm{kPa}(55$ and $59 \mathrm{mmHg}$ ). Only patients with a $\mathrm{Pa}, \mathrm{O}_{2}<6.6 \mathrm{kPa}(50 \mathrm{mmHg})$ at the time of prescription had a significantly worse survival $(\mathrm{p}<0.001)$ than the other groups. The survival of patients with a $\mathrm{Pa}, \mathrm{O}_{2} \check{\mathrm{S}} 8$ $\mathrm{kPa}$ was greatly reduced compared with that of the general population of the same age and sex as derived from French national statistics [15] (fig. 6). It should be noted that rate of entry into long-term care was similar for all groups, but the level of discontinuation of LTOT was $14 \%$ in patients with $\mathrm{Pa}, \mathrm{O}_{2} \breve{\mathrm{S}} 8 \mathrm{kPa}(60 \mathrm{mmHg})$ and only $9 \%$ in patients with $\mathrm{Pa}, \mathrm{O}_{2}<8 \mathrm{kPa}(60 \mathrm{mmHg})$.

\section{Discussion}

In a study of 7,700 patients prescribed LTOT it was shown that $18.5 \%$ of patients with a diagnosis of COPD in the ANTADIR network in France were prescribed LTOT with initial stable blood gases outside published guidelines. These patients, however, had reduced survival which was comparable to that of patients with a $\mathrm{Pa}, \mathrm{O}_{2}$ between 6.7 and $8 \mathrm{kPa}(50$ and $60 \mathrm{mmHg}$ ). They differed from the patients on LTOT, with more severe hypoxaemia being

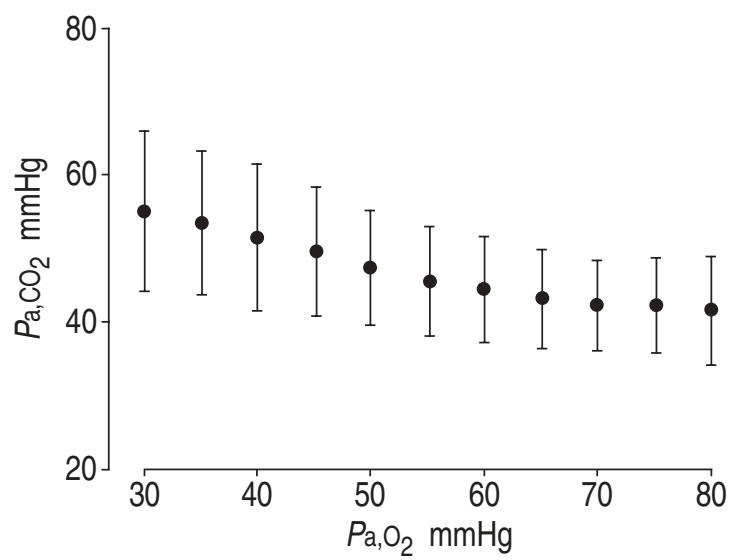

Fig. 3. - Variation in arterial carbon dioxide tension $\left(P \mathrm{a}, \mathrm{CO}_{2}\right)$ in relation to arterial oxygen tension $\left(\mathrm{Pa}, \mathrm{O}_{2}\right)$ (means \pm SD). $(1 \mathrm{mmHg}=0.133 \mathrm{kPa}$.)

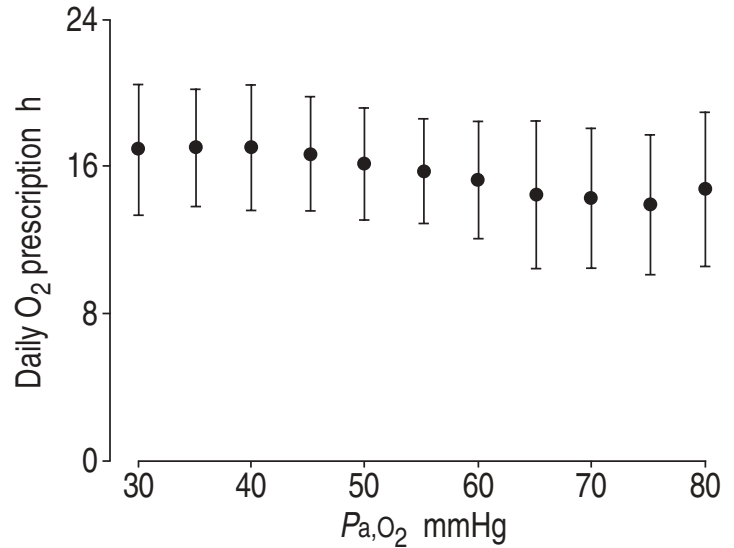

Fig. 4. - Variation in duration of oxygen therapy per day prescribed in relation to arterial oxygen tension $\left(\mathrm{Pa}_{\mathrm{O}} \mathrm{O}_{2}\right)$ (means $\left.\pm \mathrm{SD}\right) .(1 \mathrm{mmHg}=0.133$ $\mathrm{kPa}$.)

more frequently labelled as emphysema. They also had a lower $\mathrm{Pa}, \mathrm{CO}_{2}$ and a shorter duration of LTOT prescribed and were more frequently given liquid oxygen.

The results show a wide range of $\mathrm{Pa}_{\mathrm{a}} \mathrm{O}_{2}$ with a few patients having normal oxygenation. This may have been a miscoding in a few of the 7,700 patients. This wide variation in $\mathrm{Pa}, \mathrm{O}_{2}$ was associated with a constantly poor level of FEV1 of around $40 \%$ pred. This may reflect the wide range in the morphotype of patients with COPD, traditionally described as pink puffers and blue bloaters. This possibility is reinforced by the finding of a gradual increase in $P \mathrm{a}, \mathrm{CO}_{2}$ as the $P \mathrm{a}, \mathrm{O}_{2}$ declines (fig. 3), but this may also reflect the stage of evolution of the COPD. There is considerable variability in the relationship between $\mathrm{Pa}_{\mathrm{a}} \mathrm{CO}_{2}$ and FEV1 [16].

The guidelines published by academic societies or regulatory bodies are based on the two controlled studies which have proven the efficacy of LTOT in hypoxaemic COPD patients. Criteria for entry for these studies were for the Medical Research Council (MRC) study, a $\mathrm{Pa}_{2} \mathrm{O}_{2}$ between 5.3 and $8 \mathrm{kPa}(40$ and $60 \mathrm{mmHg}$ ) with one or more episodes of heart failure with ankle oedema [2], and for the Nocturnal Oxygen Therapy Trial (NOTT) study, a $\mathrm{Pa}, \mathrm{O}_{2}$ ð7.3 kPa $(55 \mathrm{mmHg})$ or a $\mathrm{Pa}, \mathrm{O}_{2}$ ð8 $\mathrm{kPa}(60 \mathrm{mmHg})$ plus either oedema, haematocrit Š55\% or P pulmonale on electrocardiography (ECG) [1]. Precise prescription rules

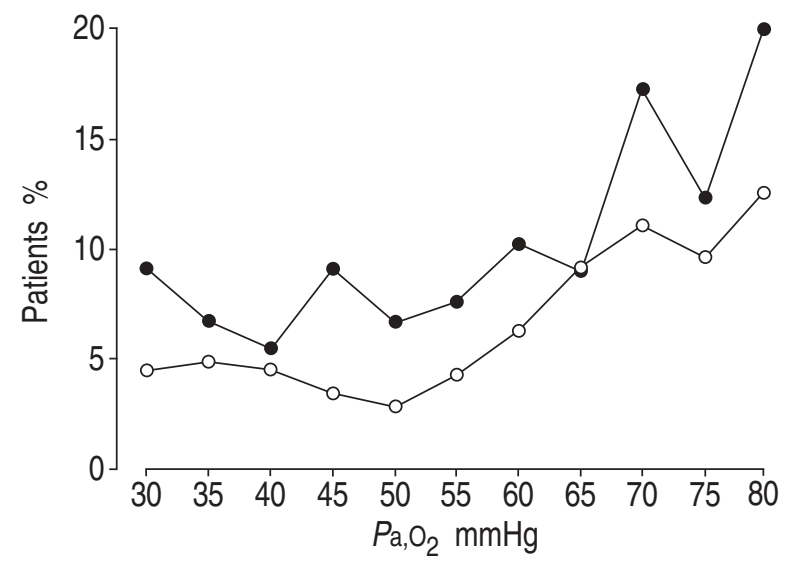

Fig. 5. - Variation in the proportion of patients with emphysema $(\bullet)$ and proportion prescribed liquid oxygen $(\mathrm{O})$ in relation to arterial oxygen tension $\left(\mathrm{Pa}, \mathrm{O}_{2}\right)$. (1 $\mathrm{mmHg}=0.133 \mathrm{kPa}$. $)$ 


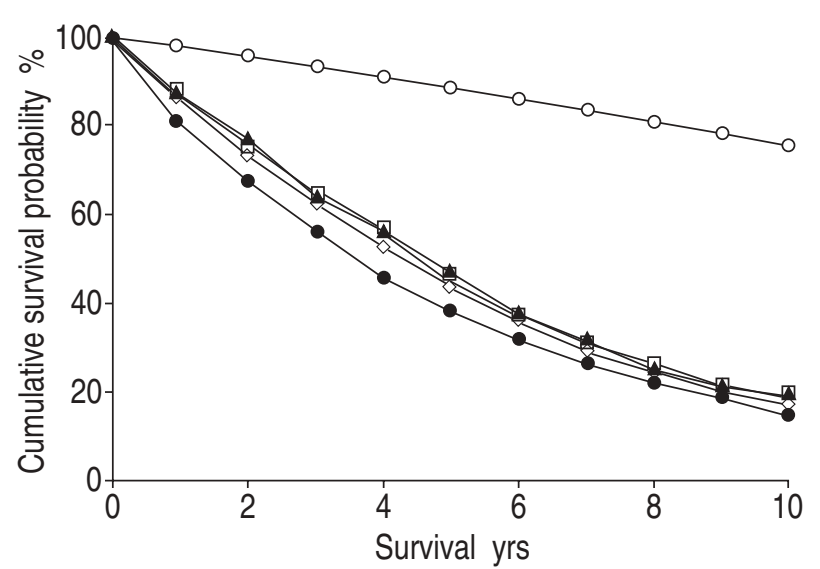

Fig. 6. - Cumulative probability of survival (yrs) at four different levels of arterial oxygen tension $\left(\mathrm{Pa}_{\mathrm{a}} \mathrm{O}_{2}\right)$ at the time of prescription of long-term oxygen therapy. Note that patients with $\mathrm{Pa}, \mathrm{O}_{2}<50 \mathrm{mmHg}$ had significantly worse survival $(\mathrm{p}<0.001)$ than the other groups and that the survival of the group with $\mathrm{Pa}, \mathrm{O}_{2}>60 \mathrm{mmHg}$ was greatly reduced compared to the general population of the same age. $\mathrm{O}$ : expected survival; $\Delta: P \mathrm{a}, \mathrm{O}_{2} \geq 60$ $\mathrm{mmHg}(8 \mathrm{kPa}) ; \mathrm{a}: \mathrm{Pa}, \mathrm{O}_{2} 55-59 \mathrm{mmHg}(7.3-7.9 \mathrm{kPa}) ; \diamond: P \mathrm{a}, \mathrm{O}_{2}$ 50-54 $\mathrm{mmHg}(6.7-7.2 \mathrm{kPa}) ; \bullet: P \mathrm{a}, \mathrm{O}_{2}<50 \mathrm{mmHg}(6.6 \mathrm{kPa}) .(0.133 \mathrm{kPa}=1$ mmHg.)

exist in France for oxygen therapy [17]. This treatment is reimbursed if $\mathrm{Pa}, \mathrm{O}_{2}$ under room air is $7.3 \mathrm{kPa}(55 \mathrm{mmHg})$ or lower at two measurements in a steady state. The minimum interval between the two measurements should be at least 2 weeks and daily oxygen treatment should be given for at least $15 \mathrm{~h}$. The reimbursement criteria also state that the prescription can be applied for the existence of polycythaemia and desaturation during sleep or exercise [18].

In the present study, $\mathrm{Pa}, \mathrm{O}_{2}$ was $>7.3 \mathrm{kPa}(55 \mathrm{mmHg})$ in $45 \%$ of patients and $>8 \mathrm{kPa}(60 \mathrm{mmHg})$ in $18 \%$. Daily oxygen was prescribed for $<15 \mathrm{~h}$ in $18 \%$ of patients $(16 \%$ in patients with $\mathrm{Pa}, \mathrm{O}_{2}<8 \mathrm{kPa}$ and $33 \%$ for patients with $\mathrm{Pa}, \mathrm{O}_{2} \check{\mathrm{S}} 8 \mathrm{kPa}$ ). Several surveys performed in the UK have shown that compliance with guidelines is often weak. In the study by WALSHAW et al. [7], 27 of 61 patients had been prescribed LTOT by a doctor other than a respira-tory specialist and only 32 of 61 patients fulfilled official criteria for the prescription of LTOT at the time of prescription of therapy. Only $54 \%$ of the patients had basal arterial oxygen saturation $\left(\mathrm{Sa}_{\mathrm{a}} \mathrm{O}_{2}\right)$ of $<90 \%$ for the study of WATERHOUSE et al. [9] and only 14\% fulfilled all of the relative criteria for the prescription of LTOT in the study of MoRRISON et al. [10]. Only RESTRICK et al. [8] observed that guidelines were largely followed.

No precise data were available on the reasons for prescription of LTOT in the group of patients with $\mathrm{Pa}_{\mathrm{a}} \mathrm{O}_{2} \breve{\mathrm{S}} 8$ $\mathrm{kPa}(60 \mathrm{mmHg})$, but it may be speculated that these patients were prescribed LTOT for nocturnal desaturation or because of exercise-related desaturation, among other causes. FlETCHER et al. [19] examined the effect of nocturnal oxygen in patients with a daytime $P \mathrm{a}, \mathrm{O}_{2}>8 \mathrm{kPa}$ and found a nonsignificant trend towards increased survival in 39 oxygen-treated versus 38 non-oxygen-treated desaturating patients, where nocturnal desaturation was defined as a fall in $\mathrm{Sa}_{\mathrm{a}} \mathrm{O}_{2}<90 \%$ for 5 min or more, with a nadir $\mathrm{Sa}_{\mathrm{a}} \mathrm{O}_{2}$ reaching $85 \%$ or less. While American guidelines do not set any criteria for nocturnal desaturation the recent French guidelines [6] would consider LTOT for nocturnal desaturation only if the patient passes over $30 \%$ of the night with a $\mathrm{Sa}, \mathrm{O}_{2}<90 \%$. These guidelines state, however, that this treatment should not yet be applied systematically but only in carefully considered cases.

Many patients who are hypoxaemic at rest worsen during exertion, while others develop hypoxaemia only during exertion. Some short-term studies have shown that supplemental oxygen during exercise can prevent transient increases in pulmonary artery pressure and pulmonary vascular resistance [20]. Home supplemental oxygen is commonly prescribed for exercise-related desaturation, even though studies designed to determine the long-term benefit of oxy-gen solely for exercise have yet to be conducted [5]. Figure 5 shows a sharp rise in the proportion of patients given liquid oxygen with a $\mathrm{Pa}, \mathrm{O}_{2}$ above $7.3 \mathrm{kPa}(55$ $\mathrm{mmHg}$ ), implying that above this figure a large proportion of pa-tients were prescribed ambulatory oxygen. These patients were more likely to have a diagnosis of emphysema and therefore have severe breathlessness and exercise-related desaturation.

Prognosis in COPD depends not on hypoxaemia alone but equally on other factors such as sex, nutritional status, type of COPD (emphysematous or bronchitic) and bronchial obstruction [11]. FEV1 is independently predictive of survival even when mildly impaired [21]. COOPER and HowARD [22] have shown that deterioration in airway function continues despite LTOT and thus reduces survival. Indeed, in the present study a $\mathrm{Pa}, \mathrm{O}_{2} 6.7 \mathrm{kPa}(50 \mathrm{mmHg})$ seems to be a more clear-cut prognostic figure for survival than $8 \mathrm{kPa}(60 \mathrm{mmHg})$, as the survival was similar for all groups of patients with a $\mathrm{Pa}, \mathrm{O}_{2}>6.7 \mathrm{kPa}$. This could reflect the beneficial effect of LTOT in hypoxaemic patients in improving the survival into the same range as that of patients with a $P \mathrm{a}, \mathrm{O}_{2}>8 \mathrm{kPa}$. AnTHonisen et al. [21] showed that oxygen therapy improved survival in patients with a $\mathrm{Pa}, \mathrm{O}_{2}$ $7.3 \mathrm{kPa}(55 \mathrm{mmHg})$ to the same level as in patients with a similar level of obstruction but without hypoxaemia $\left(\mathrm{Pa}_{\mathrm{a}} \mathrm{O}_{2}\right.$ $\check{S} 7.3 \mathrm{kPa}$ ). Randomized, controlled trials with welldefined groups of patients and an assessment of quality of life, healthcare consumption and costs are needed.

Compliance with LTOT plays a role in outcome. No precise data are available on these individual patients, but PÉPIN et al. [23] studied compliance in 950 patients in the ANTADIR network and found an average compliance of $14.5 \pm 5($ mean \pm SD) from clock counters in the concentrators. Factors influencing compliance included a reduced compliance in patients with a $P \mathrm{a}, \mathrm{O}_{2}>7.3 \mathrm{kPa}$ and the prescribed duration of LTOT. This strengthens the implication that prescription of LTOT to such patients is for effort or nocturnal desaturation.

It seems important to understand the reasons why physicians prescribe LTOT for patients with $\mathrm{Pa}, \mathrm{O}_{2}$ outside guidelines. Furthermore, prospective studies on the use of LTOT in circumstances outside those verified by the MRC and NOTT studies are needed in order to validate or justify the use of oxygen in circumstances such as nocturnal or exercise-related hypoxaemia, dyspnoea, cardiac failure, pulmonary arterial hypertension and polycythaemia.

GóRECKA et al. [24] have recently reported a randomi-zed study of survival in patients with $\mathrm{Pa}_{\mathrm{a}} \mathrm{O}_{2}$ ranging 7.4-8.7 $\mathrm{kPa}$ and found no difference between treated patients and well matched controls. Our survival curve for patients with a $\mathrm{Pa}, \mathrm{O}_{2}>8 \mathrm{kPa}$ is superimposable on that of GóRECKA et al. [24], but as we do not have a control group we can only say that survival in our groups with a $\mathrm{Pa}, \mathrm{O}_{2} 7.3-8.0$ and $>8.0 \mathrm{kPa}(55-60$ and $>60 \mathrm{mmHg}$ ) was similar when both 
groups are treated. Whether these two groups would have had the same survival if both were untreated is a vexed question which our study does not answer. Since the functional impairment as shown by FEV1 was the same in both groups one could only speculate that the same survival advantage accrued to all.

In conclusion, patients prescribed long-term oxygen therapy with an arterial oxygen tension $\mathrm{S} 8 \mathrm{kPa}(60 \mathrm{mmHg})$ in the ANTADIR network have been shown to have severe chronic obstructive pulmonary disease on the basis of spirometry. Their survival is similar to that of more hypoxaemic patients who were also treated with long-term oxygen therapy and below that of the general population of the same age and sex. The current guidelines may need revision and prospective studies of the effect of long-term oxygen therapy in these patients are needed.

Acknowledgements: The authors would like to thank all of the regional associations who provide data to the Observatory, F. Binet and M. Coisy-Vialette for invaluable assistance and J-L. Pépin for helpful criticism. Associations taking part in the ANTADIR Observatory: AIR Angers, AVD Ango-ulême, DDS Besançon, AVAD Bordeaux, AIR Caen, AIRRA ClermontFerrand, ALIZE Dijon, ADAIR Fouquières, AGIR Grenoble, GHAHR Le Havre, AVAD Lille, ALAIR Limoges, ARARD Marseille, APARD Montpellier, AIR Mulhouse, ARAIRLOR Nancy, ARIRPLO Nantes, CARDIF Paris, ARAIRCHAR Reims, AADAIRC Rochefort, ADIR Rouen, ADIRAL Strasbourg, SADIR Toulouse, ARAIR Tours, ARARR La Réunion.

\section{References}

1. Nocturnal Oxygen Therapy Trial Group. Continuous or nocturnal oxygen therapy in hypoxemic chronic obstructive lung disease: a clinical trial. Ann Intern Med 1980; 93: 391-398.

2. Report of the Medical Research Council Working Party. Long-term domiciliary oxygen therapy in chronic hypoxic cor pulmonale complicating chronic bronchitis and emphysema. Lancet 1981; i: 681-686.

3. O'Donohue WJ, Plummer AL. Magnitude of usage and cost of home oxygen therapy in the United States. Chest 1995; 107: 301-302.

4. Siafakas NM, Vermeire R, Pride NB, et al. Optimal assessment and management of chronic obstructive pulmonary disease (COPD). Eur Respir J 1995; 8: 1398-1420.

5. ATS Statement. Standards for the diagnosis and care of patients with chronic obstructive pulmonary disease. Am Rev Respir Crit Care Med 1995; 152: S77-S120.

6. Société de Pneumologie de Langue Française. Recommandations pour la prise en charge des bronchopneumopathies chroniques obstructives. Rev Mal Respir 1997; 14: 2S7-2S91.

7. Walshaw MJ, Lim R, Evans CC, Hind CR. Prescription of oxygen concentrators for long term oxygen treatment: reassessment in one district. Br Med J 1988; 297: 10301032.
8. Restrick LJ, Paul EA, Braid GM, Cullinan P, Moore-Gillon J, Wedzicha JA. Assessment and follow up of patients prescribed long term oxygen treatment. Thorax 1993; 48: 708-713.

9. Waterhouse JC, Nichol J, Howard P. Survey on domiciliary oxygen by concentrator in England and Wales. Eur Respir J 1994; 7: 2021-2025.

10. Morrison D, Skwarski K, MacNee W. Review of the prescription of domiciliary long term oxygen therapy in Scotland. Thorax 1995; 50: 1103-1105.

11. Chailleux E, Fauroux B, Binet F, Dautzenberg B, Polu JM. Predictors of survival in patients receiving domiciliary oxygen therapy or mechanical ventilation. A 10-years analysis of ANTADIR Observatory. Chest 1996; 109: 741749.

12. Dubois P, Jamart J, Machiels J, Smeets-F, Lulling J. Prognosis of severely hypoxemic patients receiving long-term oxygen therapy. Chest 1994; 105: 469-474.

13. Ström K, Boe J. Quality assessment and predictors of survival in long-term domiciliary oxygen therapy. The Swedish Society of Chest Medicine. Eur Respir J 1991; 4: 50-58.

14. Quanjer PH. Standardized lung function testing. Summary of recommendations. Bull Eur Physiopathol Respir 1983; 19: Suppl. 5, 7-10.

15. Couet C, Court Y. La situation demographique en 1990. Mouvement de la population. INSEE résultats 1992; no. 16-17, p. 288.

16. Lane DJ, Howell JBL, Giblin B. Relation between airways obstruction and $\mathrm{CO}_{2}$ tension in chronic obstructive airways disease. Br Med J 1968; iii: 707-709.

17. Matériels et appareils médicaux pour traitement à domicile - TIPS. J Officiel 1992; 4: 15-16.

18. Gries RE, Brooks LJ. Normal oxyhemoglobin saturation during sleep: how low does it go? Chest 1996; 110: 1489-1492.

19. Fletcher EC, Donner CF, Midgren B, et al. Survival in COPD patients with a daytime $P \mathrm{a}, \mathrm{O}_{2}>60 \mathrm{mmHg}$ with and without nocturnal oxyhemoglobin desaturation. Chest 1992; 101: 649-655.

20. Dempsey JA, Vidruk EH, Westenbrook SM. Pulmonary control systems in exercise. Fedn Proc 1980; 39: 14981505.

21. Anthonisen NR, Wright EC, Hodgkin JE, IPPB Trial Group. Prognosis in chronic obstructive disease. Am Rev Respir Dis 1986; 133: 14-20.

22. Cooper CB, Howard P. An analysis of sequential physiologic changes in hypoxic cor pulmonale during long-term oxygen therapy. Chest 1991; 100: 76-80.

23. Pépin JL, Barjhoux CE, Deschaux C, Brambilla C, ANTADIR Working Group on Oxygen Therapy. Long term oxygen therapy at home: compliance with medical prescription and effective use of therapy. Chest 1995; 109: $1144-1150$.

24. Górecka D, Gorzelak K, Śliwiński P, Tobiasz M, Zieliński J. Effect of long-term oxygen therapy on survival in patients with chronic obstructive pulmonary disease with moderate hypoxaemia. Thorax 1997; 52: 674-679. 